\title{
Una Nueva Localidad de Zeolitas Volcanosedimentarias en México
}

\section{Ríos Garcia, Raquel*y Badilla Cruz, Ramón* \\ INTRODUCCION}

Las zeolitas son aluminio-silicatos hidratados de metales alcalinos y alcalino-térreos. Hasta la fecha han sido caracterizadas alrededor de 35 especies minerales pertenecientes a este grupo. Conocidas desde hace mucho tiempo como minerales secundarios, encontrados principalmente rellenando vesículas y fisuras en rocas ígneas básicas, no fue sino hasta los últimos 20 a 30 años, con la utilización de técnicas de investigación modernas, que fueron identificadas como principales constituyentes en rocas sedimentarias de origen volcánico (tobas híbridas) o de metamorfismo de bajo grado.

Sus propiedades físico-químicas excepcionales, derivadas de su estructura cristalina con kmplios huecos y canales que permiten el paso de hones y moléculas variados, han propiciado su utiliż creciente como intercambiadores iónicos (ôtbas moleculares), catalizadores, purificadores de tagua y desechos radiactivos, agregados de alimentós para aves y ganado, agregados en fertilizantes, én cementos, en materiales de construcción, etc. (MunsonSheppard, 1974).

Como consecuencia de sis variadas aplicaciones, las zeolitas naturales han despertado un gran interés por ser bastante más baratas que las artificiales; de ahí que recientemente se ha intensificado, internacionalmente, la prospección y estudio de nuevos yacimientos y la investigación de mayores usos industriales.
En México hay posibilidades de contar con grandes yacimientos de zeolitas, derivados de los abundantes depósitos de rocas tobáceas del Mesozoico Superior y Cenozoico, que seguramente se reportarán cuando sean debidamente estudiados. El primer yacimiento de este tipo en el país sobre el que se ha publicado un trabajo (Mumpton, 1973 a), es el de Etla, Oaxaca, que corresponde a un ignimbrita verdosa zeolitizada, utilizada ampliamente desde tiempos prehispánicos como material de construcción en la Cd. de Oaxaca y sus alrededores. De otros yacimiêntos se tienen referencias inéditas (Mumpton, 1975), como es el caso de una toba zeolitizada de San Luis Potosí, reconocida por De Pablo y otras ocurrencias en el estado de Oaxaca encontradas por Mumpton, Ferrusquía y Rodríguez.

La presencia de zeolitas en el yacimiento objeto de este estudio fue descubierta al enviar el Ing. Ramón Fernández, Director de la Sucursal Hermosillo de la Comisión de Fomento Minero, al laboratorio de la Unidad Tecamachalco de la misma institución, una muestra para su identificación mineralógica.

La muestra de referencia, fue estudiada por los suscritos por difracción de rayos $\mathrm{X}$ y en dicho estudio se determinó la existencia de abundante zeolita, entre otros minerales. Posteriormente, dada la ausencia relativa de estudios detallados de este tipo de yacimientos en México, se creyó conveniente realizar una investigación de este depósito tendiente a determinar su génesis basándose en criterios texturales, estructurales, mineralógicos y litológicos. 


\section{Una Nueva Localidad de Zeolitas Volcanosedimentarias en México}

\section{Rios Garcia, Raquel"y Badilla Cruz, Ramón* \\ INTRODUCCION}

Las zeolitas son aluminio-silicatos hidratados de metales alcalinos y alcalino-térreos. Hasta la fecha han sido caracterizadas alrededor de 35 especies minerales pertenecientes a este grupo. Conocidas desde hace mucho tiempo como minerales secundarios, encontrados principalmente rellenando vesículas y fisuras en rocas ígneas básicas, no fue sino hasta los últimos 20 a 30 años, con la utilización de técnicas de investigación modernas, que fueron identificadas como principales constituyentes en rocas sedimentarias de origen volcánico (tobas híbridas) o de metamorfismo de bajo grado.

Sus propiedades físico-químicas excepeignales, derivadas de su estructura cristalina cohtomplios huecos y canales que permiten el paso dehries y moléculas variados, han propiciado su utilizấn creciente como intercambiadores iónicos (Gabas moleculares), catalizadores, purificadores de ragua y desechos radiactivos, agregados de alimentós para aves y ganado, agregados en fertilizantes, én cementos, en materiales deconstrucción, etc. (MunsonSheppard, 1974).

Como consecuencia de sils variadas aplicaciones, las zeolitas naturales han despertado un gran interés por ser bastante más baratas que las artificiales; de ahí que recientemente se ha intensificado, internacionalmente, la prospección y estudio de nuevos yacimientos y la investigación de mayores usos industriales.

\footnotetext{
.. : : ' In Fomento Minero.
}

En México hay posibilidades de contar con grandes yacimientos de zeolitas, derivados de los abundantes depósitos de rocas tobáceas del Mesozoico Superior y Cenozoico, que seguramente se reportarán cuando sean debidamente estudiados. El primer yacimiento de este tipo en el país sobre el que se ha publicado un trabajo (Mumpton, 1973 a), es el de Etla, Oaxaca, que corresponde a un ignimbrita verdosa zeolitizada, utilizada ampliamente desde tiempos prehispánicos como material de construcción en la Cd. de Oaxaca y sus alrededores. De otros yacimientos se tienen referencias inéditas (Mumpton, 1975), como es el caso de una toba zeolitizada de San Luis Potosí, reconocida por De Pablo y otras ocurrencias en el estado de Oaxaca encontradas por Mumpton, Ferrusquía y Rodríguez.

La presencia de zeolitas en el yacimiento objeto de este estudio fue descubierta al enviar el Ing. Ramón Fernández, Director de la Sucursal Hermosillo de la Comisión de Fomento Minero, al laboratorio de la Unidad Tecamachalco de la misma institución, una muestra para su identificación mineralógica.

La muestra de referencia, fue estudiada por los suscritos por difracción de rayos $\mathrm{X}$ y en dicho estudio se determinó la existencia de abundante zeolita, entre otros minerales. Posteriormente, dada la ausencia relativa de estudios detallados de este tipo de yacimientos en México, se creyó conveniente realizar una investigación de este depósito tendiente a determinar su génesis basándose en criterios texturales, estructurales, mineralógicos y litológicos. 
Este yacimiento se localiza en el Ejido de San Pedro, Municipio de Ures, Estado de Sonora, aproximadamente a $15 \mathrm{~km},(30 \circ \mathrm{NE}$ en línea recta de la población de Ures), geográficamente queda comprendido entre las coordenadas 29031' de latitud Norte y $110^{\circ} 20^{\prime}$ de longitud Oeste (Figura No. 1), a una altitud aproximada de $700 \mathrm{~m}$, sobre el nivel. del mar.

La principal vía de acceso es la carretera estatal Ures-Masocahui, donde en el km, 70.2 se aparta hacia el Norte una brecha de $7.0 \mathrm{~km}$, de longitud, que conduce al yacimiento; esta brecha solo es transitable por vehículos de doble tracción o de rodada alta.

\section{GEOLOGIA DEL YACIMIENTO}

La geología de la región es sumamente senci1la, pues en ella solo intervienen dos unidades litológicas que no presentan grandes complicaciones tectónicas, mismas que se describen a continuación:

\section{Granito de Hornblenda y Biotita.}

Es la unidad más antigua expuesta en la zona y la más ampliamente distribuida en la porción sur; presenta un color rosado con puntos negros y ver-

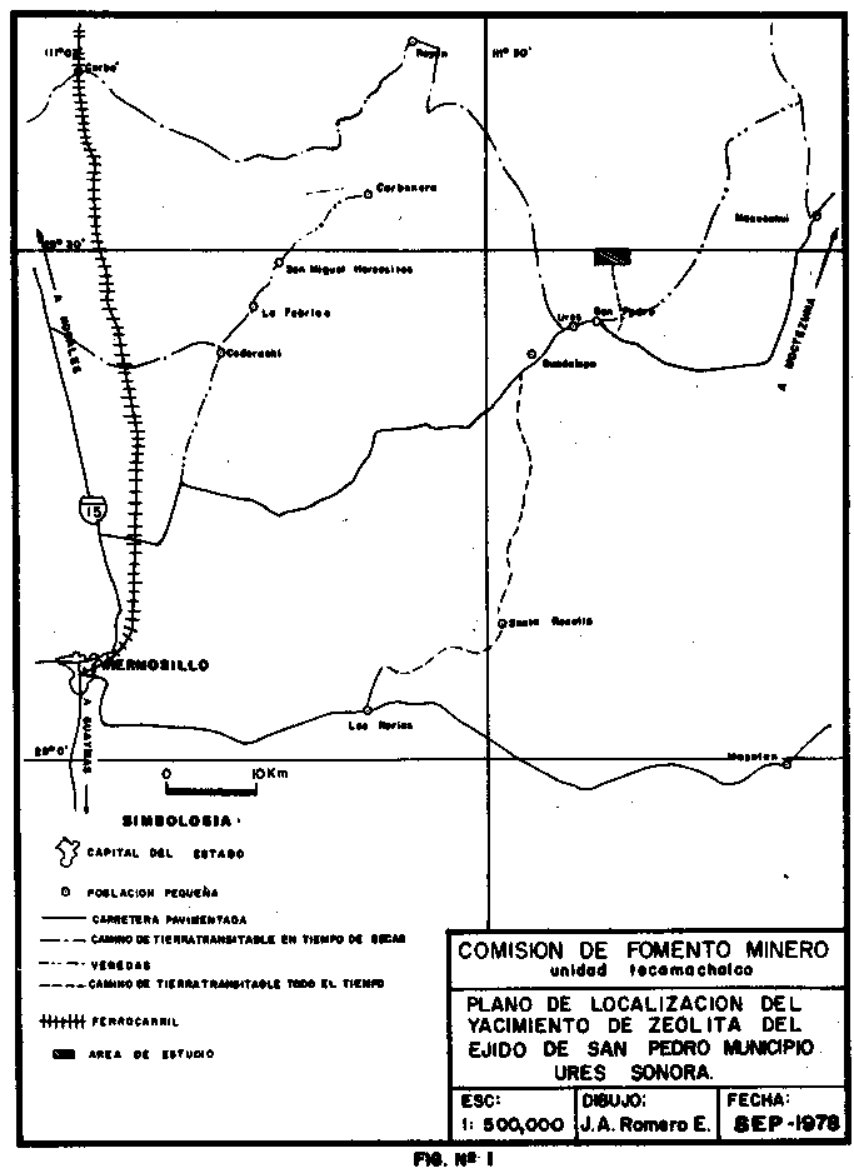

des, textura fanerítica de grano grueso y estructura compacta y masiva; se encuentra constituida por ortoclasa, microclina, oligoclasa, andesina y cuarzo, como minerales esenciales; apreciándosele hornblenda y biotita como accesorios característicos. En algunos lugares es notorio que la textura fanerftica que presenta gradúa a pegmatítica sin aparente cambio en la composición.

Es probable que esta unidad corresponda al batolito de Sonora, pero no se cuenta con la información regional suficiente para sostener esta afirmación.

\section{Arenisca Tobácea Zeolitizada.}

Estratigráficamente, arriba y en discordancia con la unidad de granito de hornblenda y biotita, descansa una arenisca tobácea de color gris claro, de textura en partes clástica y en otras piroclástica, que en su parte basal predomina la estratificación gradual y en su porción media y superior la estratificación gradual, cruzada $y$ huellas de desecación rellenadas por arena y ceniza volcánica (Figura No. 1,2 y 3, Lámina 1). En general esta roca, se encuentra constituída por fragmentos angulosos, euhedrales, subhedrales, subredondeados y redondeados de cuarzo, oligoclasa, andesina, ortoclasa, microclina, sanidino, biotita y vidrio, la penúltima alterada casi totalmente a clorita y el último a un mineral de apariencia arcillosa, que en estudios practicados por Difracción de Rayos X, resultó ser zeolita; además se aprecia que este mineral es el responsable de la litificación de los fragmentos, por lo que se encuentra actuando como matriz.

En la parte media de esta unidad presenta algunos horizontes de marcado aspecto conglomerático, en donde los fragmentos redondeados y subredondeados que le dan este carácter, son principalmente fragmentos del granito de hornblenda y biotita descrito con anterioridad y de una roca volcánica ácida. También en esta porción, pero estratigráficamente arriba del horizonte conglomerático, dividido de él por un horizonte de arenisca tobácea zeolitizada con estratificación cruzada, de aproximadamente 2.0 metros de espesor, se encuentra interestratificada en aparente discordancia, un cuerpo de toba híbrida sumamente zeolitizada que constituye el yacimiento, el que presenta un espesor promedio de 1.55 metros y se encuentra encajonado por una arenisca tobácea con marcada estratificación cruzada (Figura No. 4, Lámina I). 


\section{DESCRIPCION MEGASCOPICA Y MICROSCO- PICA DEL DEPOSITO}

El yacimiento objeto de este estudio está representado por un cuerpo estratiforme de toba híbrida sumamente zeolitizada de 1.55 metros de espesor. (Figura No. 2 y Figura No. 4, Lámina I).

Es de color crema o blanco, de textura piroclástica-clástica relicta y estratificación gradual y cruzada; se encuentra constituida por menos del $10 \%$ de fragmentos angulosos y subredondeados de feldespatos, cuarzo, arcilla y biotita, asociados a relictos de fragmentos de vidrio sumamente alterados, que en conjunto desarrollan un arreglo textural piroclástiço-clástico.

El componente más abundante de esta roca son los fragmentos de vidrio, que en general presentan formas angulosas, la mayoría de ellos totalmente alterados a un mineral de birrefrigencia baja de apariencia arcillosa, que en estudios practicados por difracción de rayos $\mathrm{X}$ se identificó como zeolita; estos fragmentos de vidrio totalmente zeolitizados se aprecian en el microscopio petrográfico como fantasmas de granos 'debido a que apenas es perceptible su contorno ya que este material zeolítico, formado por reemplazamiento del vidrio, se encuentra actuando como matriz (Figura No. 1 y 2, Lámina II). También se encontró la presencia de vidrio parcialmente reemplazado por zeolita pero en muy baja proporción, este reemplazamiento como se puede apreciar en las figuras No. 3 y 4, lámina II es un reemplazamiento guiado, llevado a cabo a través de los bordes y fracturas de los fragmentos y es una evidencia muy fuerte para ayudarnos a comprender parcialmente este proceso de zeolitización del vidrio volcánico.

Las especies de feldespatos presentes en el depósito son principalmente oligoclasa $\mathrm{y}$ andesina que se encuentran en cristales angulosos, euhedrales subhedrales y muy escasos subredondeados y redondeados; en general estos minerales se presentan también reemplazados por el mismo mineral que reemplaza al vidrio, principalmente a través de sus bordes (Figuras No. 5 y 6, Lámina II), el cuarzo representa entre el 2 y el $3 \%$ del total de los minerales del depósito y sus granos presentan las mismas formas que los feldespatos descritos con anterioridad. La biotita representa aproximadamente el $0.5 \%$ y se encuentra alterada a clorita a través de sus planos de crucero y la arcilla se presenta en nódulos diseminados principalmente en los estratos inferiores del depósito.

Con el propósito de conocer más objetivamente el fenómeno de zeolitización de los componen- tes primarios principales del depósito, se creyó conveniente estudiar algunas muestras en el microscopio electrónico de barrido, observándose en este estudio en imágenes de electrones secundarios. una avanzada zeolitización de los fragmentos evidenciada por la presencia de abundantes cristales euhedrales, tabulares de aparente simetría monoclínica alrededor de los fragmentos alterados (Figura No. 1, 2 y 3, Lámina III).

\section{IDENTIFICACION DE LA ESPECIE DE ZEOLITA}

El único medio seguro y definitivo para la identificación de las zeolitas es su estudio por Difracción de rayos $\mathrm{X}$. Las demás técnicas, como termoanálisis, microscopía óptica y electrónica, análisis químico, etc., complementan su investigación y en algunos casos confirman la especie mineral de zeolita.

La muestra objeto de este estudio, fue sometida a la mayoría de las técnicas mencionadas, las que se describen a continuación así como los resultados a que se llegó.

\section{DIFRACCION DE RAYOS X}

Los difractogramas fueron obtenidos en un aparato Philips, utilizando radiación $\mathrm{K} r$ de $\mathrm{Cu}$ y

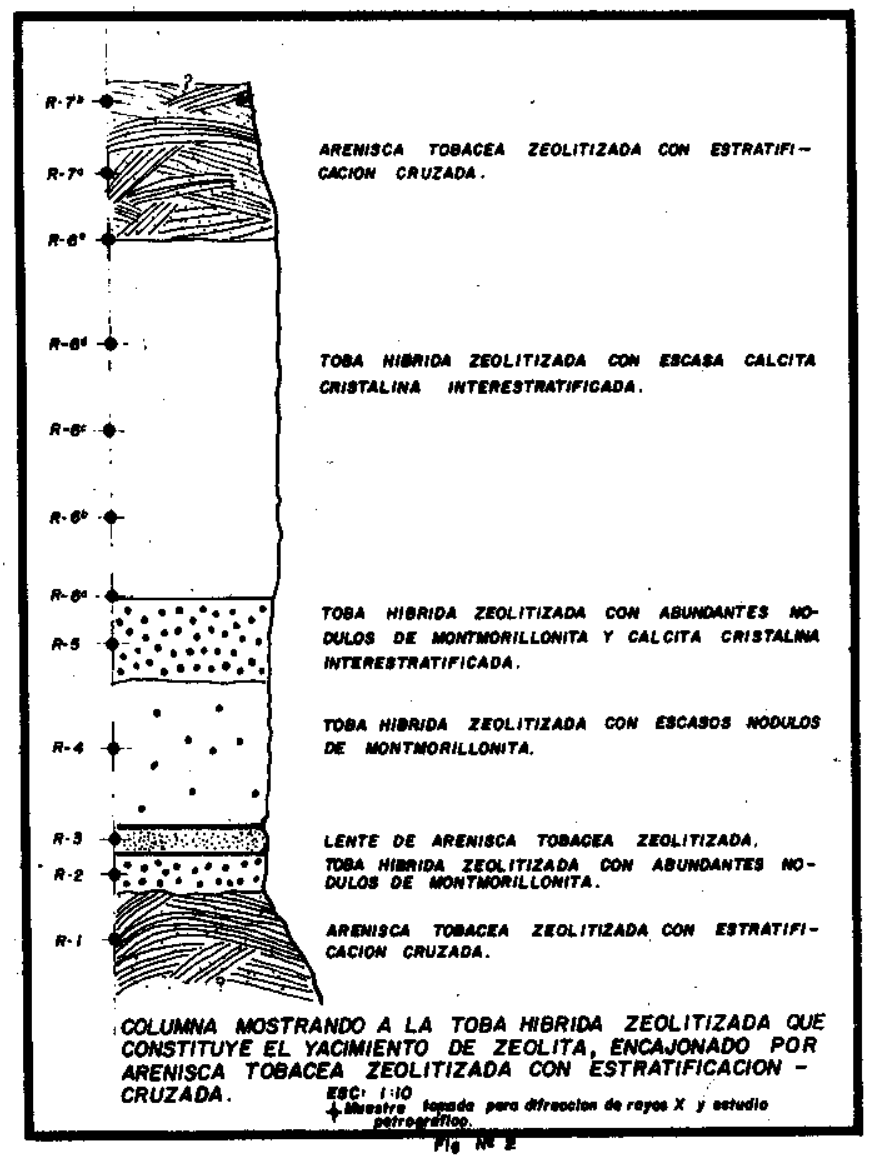


monocromador de $\mathrm{LiF}$. Fueron analizadas por esta técnica todas las muestras colectadas en el afloramiento estudiado (Figura No. 2), las que corresponden a una de cada capa diferenciada y una cada $20 \mathrm{~cm}$ en los estratos zeolitizados de la parte superior del yacimiento. Las muestras, siguiendo un orden de la base a la cima del afloramiento, contienen las especies minerales cristalizadas que se anotan en la figura No. 3, donde están presentadas, lateralmente en orden decreciente de la proporción estimada.

Es claramente notable un zoneamiento en la proporción de zeolita, aumentando hacia el estrato marcado $R-6$, en el cual su contenido es bastante alto, probablemente alrededor de $90 \%$.

De la parte media de dicho estrato se tomó la muestra para efectuar las determinaciones de la figura No. 4.

\begin{tabular}{|c|c|c|c|c|}
\hline \multirow{2}{*}{$\begin{array}{l}\text { MUESTRA } \\
\text { NO. }\end{array}$} & \multicolumn{2}{|c|}{ ESPECIES } & \multicolumn{2}{|c|}{ Y INEAALES } \\
\hline & MAYOR & MEDIANA & MENOR & PEQUENA \\
\hline R-1 & $\mathbf{F}$ & $\mathbf{a}$ & $\mathrm{Z}, \mathrm{Mo}, \mathrm{Mi}$ & \\
\hline R-2 & M & & $\mathbf{F}, \mathbf{Z}, \mathbf{Q}$ & \\
\hline $\mathbf{R}-\mathbf{3}$ & $\mathbf{F}$ & $0, z$ & & Mo,Mi \\
\hline$R-4$ & $\mathbf{z}$ & & $F, 0, M_{0}$ & $\mathbf{M i}$ \\
\hline h -5 & M & $Z, C$ & & $\mathbf{a}$ \\
\hline$R-6 a$ & $\mathbf{z}$ & Mo & $\mathbf{F}, \mathbf{0}$ & Mi \\
\hline$R-6 c$ & $\mathbf{z}$ & & F, Q, Mo & Mi \\
\hline $\mathbf{R}-\mathbf{6 e}$ & $\mathbf{z}$ & & $F, \mathbf{Q}, M_{0}$ & Mi \\
\hline$R-7 a$ & $\mathbf{Z}$ & & $\mathbf{F , 0}$ & $\mathrm{Mo}, \mathrm{Mi}_{\mathrm{i}}$ \\
\hline$R-7 e$ & $\mathbf{F}$ & 0,2 & $\vdots$ & $\mathrm{Mo}, \mathrm{Mi}$ \\
\hline
\end{tabular}

Fig. 3

Figura No. 3 Mineralogía de la columna (Figura No. 2) determinada por difracción de rayos $\mathrm{X}$. Símbolos: $\mathrm{C}=$ calcita, $\mathrm{F}=$ feldespatos, $\mathrm{Mi}=$ mica, Mo $=$ montmorillonita, $\mathrm{Q}=$ cuarzo, $\mathrm{Z}=$ zeolita.

Del diagrama de rayos $\mathrm{X}$ (Figura No. 4-A) se determinó que los valores de las distancias interplanares "d" corresponden a la estructura de una zeolita del tipo clinoptilolita-heulandita, especie sujeta aún a controversias, pues algunos autores se refieren a la clinoptilolita como una variedad de la heulandıta, pero más rica en $\mathrm{Si}, \mathrm{Na}$ y $\mathrm{K}$ y otros insisten en que realmente se trata de dos especies minerales, con estructua cristalina muy semejante pero con características físico-químicas diferenciables.

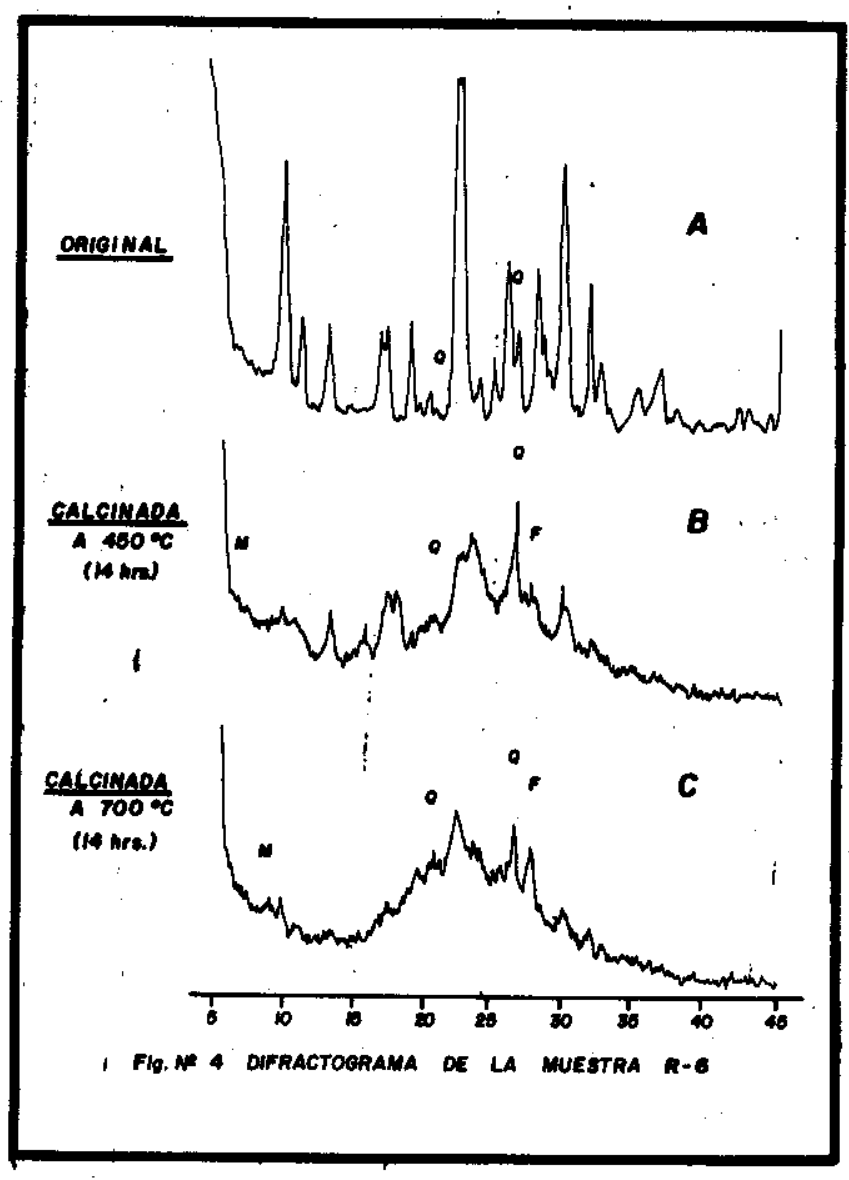

A fin de confirmar la identificación de la zeolita de Ures, se reprodujeron algunas de las pruebas reportadas por Mumpton (1960), Boles (1972) y Alietti (1972), que incluyen el tratamiento térmico de la muestra a temperaturas de $4500^{\circ} \mathrm{C}$ y $700{ }^{\circ} \mathrm{C}$ durante toda la noche (14 hrs.), tomando su difractograma correspondiente (Figuras 4 B y C). Mumpton (1960) menciona la diferencia en la intensidad de algunas reflexiones del diagrama de rayos $X$ producido por heulandita y clinoptilolita. De acuerdo a su criterio y a los ejemplos que presenta, el de la muestra estudiada corresponde a clinoptilolita.

Por otra parte, menciona que el calentamiento prolongado, a $4500^{\circ} \mathrm{C}$ destruye la estructura cristalina de la heulandita y no afecta sensiblemente a la clinoptilolita, la cual resiste hasta $750^{\circ} \mathrm{C}$. En nuestro caso se muestra en los diagramas $\mathrm{B}$ y $\mathrm{C}$ de la figura 4 , la estructura cristalina de la zeolita no fue totalmente destruída, pero sí se afectó notablemente, disminuyendo la intensidad de las reflexiones $y$ algunas distancias interplanares, lo cual no aclara definitivamente la identificación del mineral. 


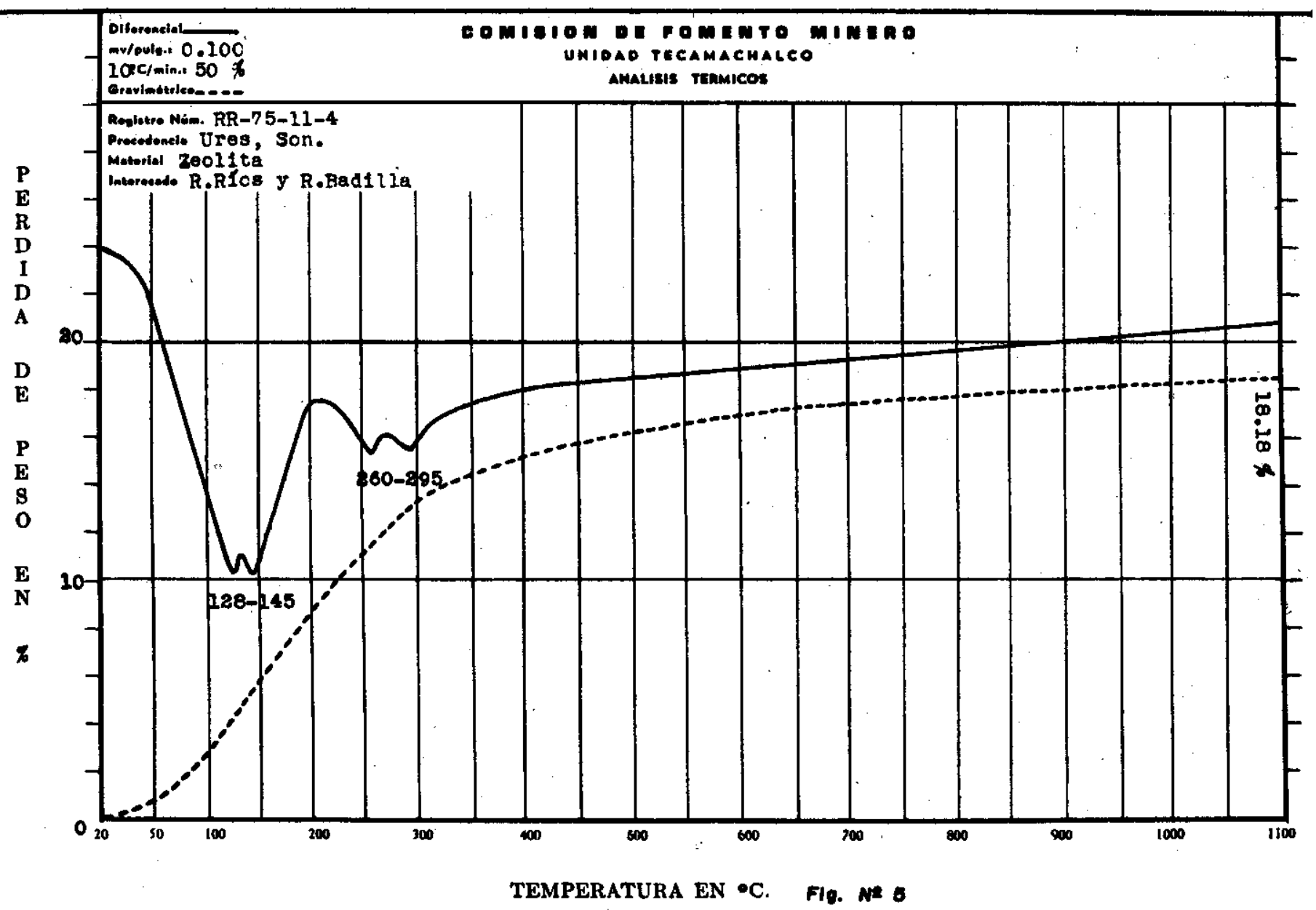

\section{TERMOANALISIS}

El Análisis Térmico Diferencial fue efectuado en un equipo marca Deltatherm, con programa de calentamiento de $10 \circ \mathrm{C} / \mathrm{min}$., y atmósfera de argón, desde la temperatura ambiente hasta 1,1000C. El termograma producido (línea continua, Figura No. 5), presenta dos reacciones endótermicas dobles, con máximos a $128-145$ y $260-2950 \mathrm{C}$. La primera de ellas corresponde a la deshidratación de la zeolita y la escasa montmorillonita presente en la muestra. La otra se atribuye a un cambio de fase, semejante al descrito por Boles (1972) para la transformación de heulandita normal a heulandita B y heulandita I. El Análisis Termogravimétrico (línea discontinua, figura No. 5) muestra la pérdida de peso en el material, debida principalmente al contenido de agua de la zeolita, siendo de $18.18 \%$ o.

\section{INDICE DE REFRACCION.}

Es variable en este tipo de minerales, dependiendo de su composición química, que no es muy definida y de la posibilidad de efectuarse sobre cristales puros, condición difícil de llenar; pero en general está considerado que la heulandita tiene un fndice de refracción mayor de 1.488 y la clinoptilolita menor de 1.485 .

En el caso que nos ocupa la medición fue ligeramente superior a 1.500 , lo que corresponde mejor con la heulandita.

\section{COMPOSICION QUIMICA.}

La composición química de heulandita y clinoptilolita, reportada en los trabajos mencionados, es bastante variable y en muchos casos poco confiable por la dificultad de purificar estos minerales. Sus fórmulas más bien son empíricas, considerando en las tarjetas patrón de rayos $\mathrm{X}$ a la heulandita co-

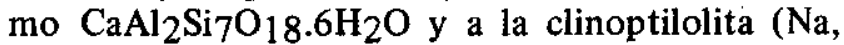
$\mathrm{K}$, Ca) $\mathrm{Al}_{2} \mathrm{SigO}_{18} .6-7 \mathrm{H}_{2} \mathrm{O}$, donde es evidente que esta última es más rica en silicio, contiene además sodio y potasio y consecuentemente, menos calcio, sin embargo, en la práctica se presentan todas las graduaciones entre las dos fórmulas, causadas en parte por la gran capacidad de intercambio iónico de las zeolitas y lo difícil de separar la especie pura, como ya se mencionó. 
En vista de lo anterior, no se consideró necesario para el objetivo de este trabajo, efectuar los análisis químicos, ya que un análisis cualitativo espectrográfico mostró como elementos principales $\mathrm{Si}$ y $\mathrm{Al}$, menores $\mathrm{Ca}, \mathrm{K}, \mathrm{Na}, \mathrm{Mg}, \mathrm{Fe}$ y $\mathrm{Sr}$, lo cual podría llevar a la conclusión de que la composición de la zeolita se ajusta mejor a la de la clinoptilolita, pero conteniendo además el mineral feldespatos, cuarzo, restos de vidrio sin alterar, montmorillonita, mica, etc., no es posible por el momento obtener la composición exacta de la especie de zeolita.

\section{MICROSCOPIA ELECTRONICA DE BARRIDO (SEM).}

Un trabajo reciente de Mumpton (1976) cita que la morfología de las zeolitas, observada en SEM, puede proporcionar datos muy útiles sobre su identificación y los diferentes pasos en el proceso de su formación a partir de un vidrio volcánico. Las imágenes obtenidas por electrones secundarios en un equipo JEOL, en pequeñas cavidades intergranulares de la muestra estudiada (Figuras Nos. 1, 2 y 3, Lámina III), son muy semejantes a las publicadas para la clinoptilolita en el trabajo mencionado, con cristales de tamaño entre 5 y 10 micras de longitud, que por otra parte son similares a los de heulandita pero muy diferentes a los de otras especies de zeolitas comunmente encontradas en este tipo de yacimientos.

En resumen, la zeolita de Ures parece corresponder, por las características anteriormente descritas, a un tipo intermedio entre clinoptilolita y heulandita aunque su baja estabilidad al tratamiento térmico, prueba considerada como diagnóstica por algunos autores, la acerca más a la heulandita. Sería recomendable en trabajos posteriores, obtener su análisis químico por medio de Microsonda Electrónica (EMP) para su caracterización definitiva, de acuerdo a las relaciones $\mathrm{Si} / \mathrm{Al}, \mathrm{Ca} /(\mathrm{Na}+$ K), etc., citadas por Alietti (1972) y Boles (1972).

En los estudios efectuados no fue observada ninguna otra zeolita asociada a la clinoptilolitaheulandita, como suele ocurrir frecuentemente en estos minerales, por ejemplo el caso de la Etla, Oax. (Mumpton, 1973 a), donde coexisten clinoptilolita y mordenita.

\section{GENESIS DEL YACIMIENTO Y CLASIFICACION}

Los yacimientos de zeolitas derivados de rocas sedimentarias de origen piroclástico, son el resultado de la reacción entre cenizas volcánicas vítreas y aguas meteóricas o connatas salinas--alcalinas. La obtención en laboratorio de varias zeolitas a partir de vidrio volcánico y soluciones de carbonatos alcalinos, a presiones y temperaturas relativamente bajas, ha comprobado el mecanismo y las condiciones de su formación.

Basándose en su localización geológica, composición mineralógica $\mathrm{y}$ origen, las zeolitas se han clasificado, en general, en los siguientes grupos (Mumpton, 1976).

a) Depósitos formados de material volcánico en sistemas "cerrados" de lagos salinos.

b) Depósitos formados en sistemas "abiertos" en lagos de agua dulce o subterránea.

c) Depósitos formados en ambientes marinos.

d) Depósitos formados por metamorfismo de sepultamiento de bajo grado.

e) Depósitos formados por actividad hidrotermal o de manantiales termales.

f) Depósitos formados de restos volcánicos o minerales arcillosos en suelos alcalinos.

g) Depósitos formados sin evidencias directas de precursores volcánicos.

Los yacimientos de interés comercial son únicamente los primeros tres tipos, por su gran volumen.

En el caso del depósito objeto de este estudio, los autores consideran que se originó por el depósito $\mathrm{y}$ alteración de material piroclástico (Cenizas volcánicas vítreas) en un ambiente fluvial o lacustre, debido a que en la unidad que encajona al yacimiento, se encontró la presencia de horizontes conglomeráticos, huellas de desecación y estratificación gradual y cruzada que son comunes en ambos ambientes de depósito; otra evidencia más para reforzar el ambiente de depósito anteriormente considerado, es que la zeolita que constituye el yacimiento corresponde a la serie clinoptilolita-heulandita y que no está asociada a evaporitas lo que nos denota, según algunos autores, que el agua que provocó la zeolitización era agua dulce (Mumpton 1976).

Los autores consiteran como medio de depósito más probable para esta zeolita el ambiente lacustre, puesto que si fuera fluvial se hubiera necesitado que los componentes de la roca estuvieran por largo liempn saturados de aguas freáticas con contenidos de " $\mathrm{c}$ " " $y$ sales; si esto hubiera sucedido la zeolitizacióni se hubiera efectuado de todo el vi- 


\section{LAMINA I}

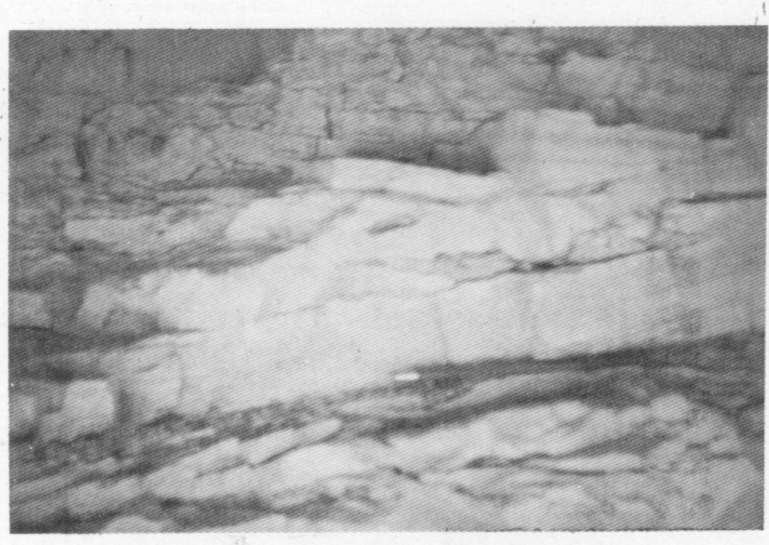

Fig. 1.- Estratificación cruzada en la arenisca tobácea.

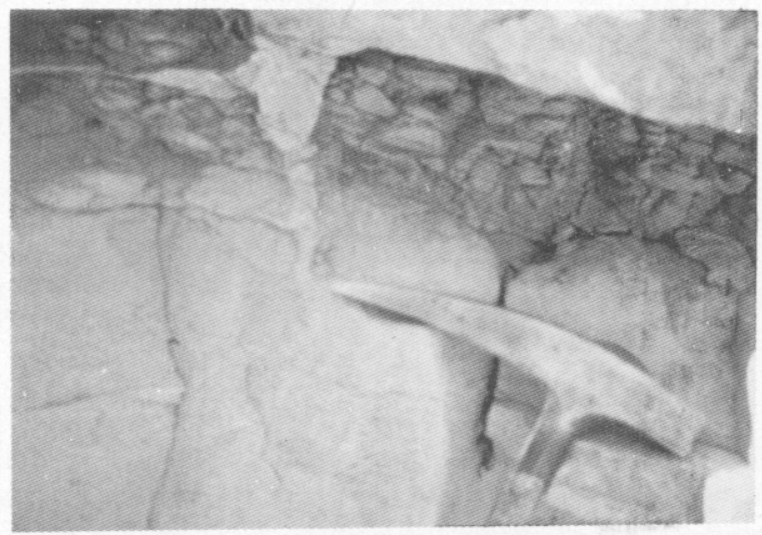

Fig. 3.- Huella de desecación rellenada por arena y ceniza volcánica en la arenisca tobácea.

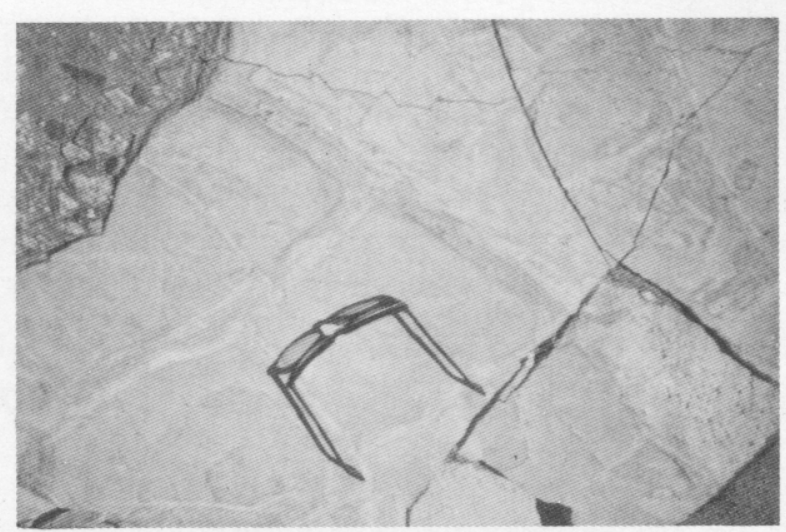

Fig. 2.- Huellas de desecación en la arenisca tobácea.

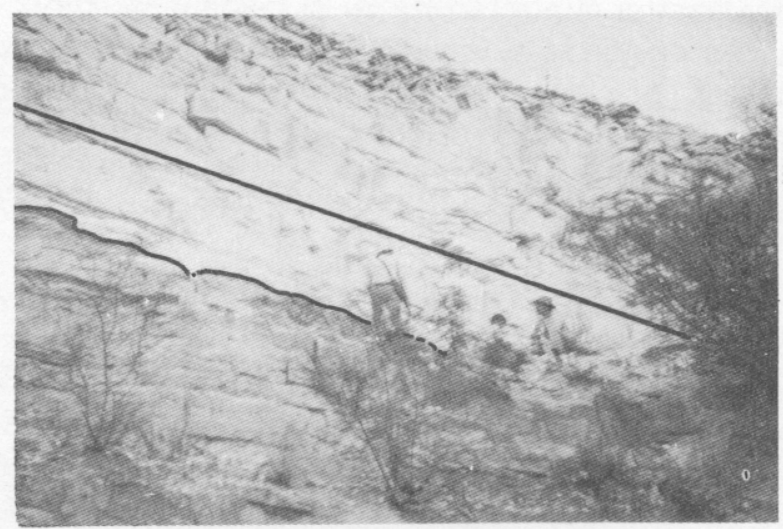

Fig. 4.- Muestra el cuerpo de toba híbrida sumamente zeolitizada que constituye al yacimiento encajonado por una arenisca tobácea.

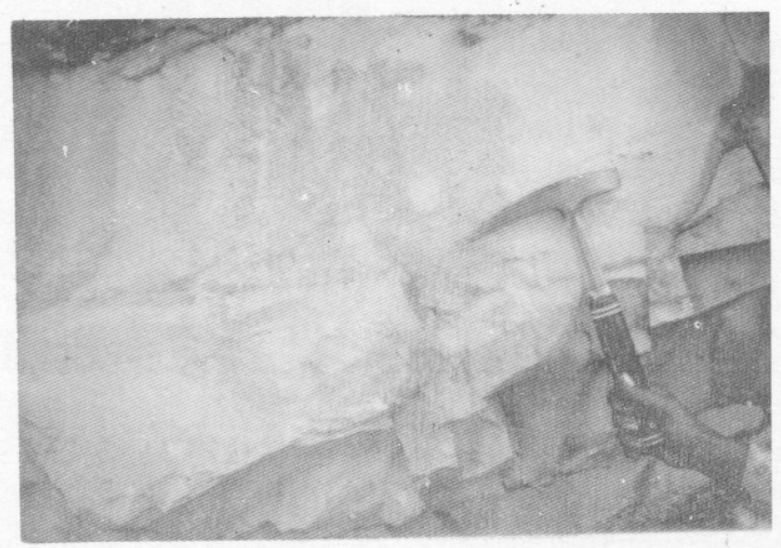

Fig. 5.- Estratificación cruzada en el depósito. 

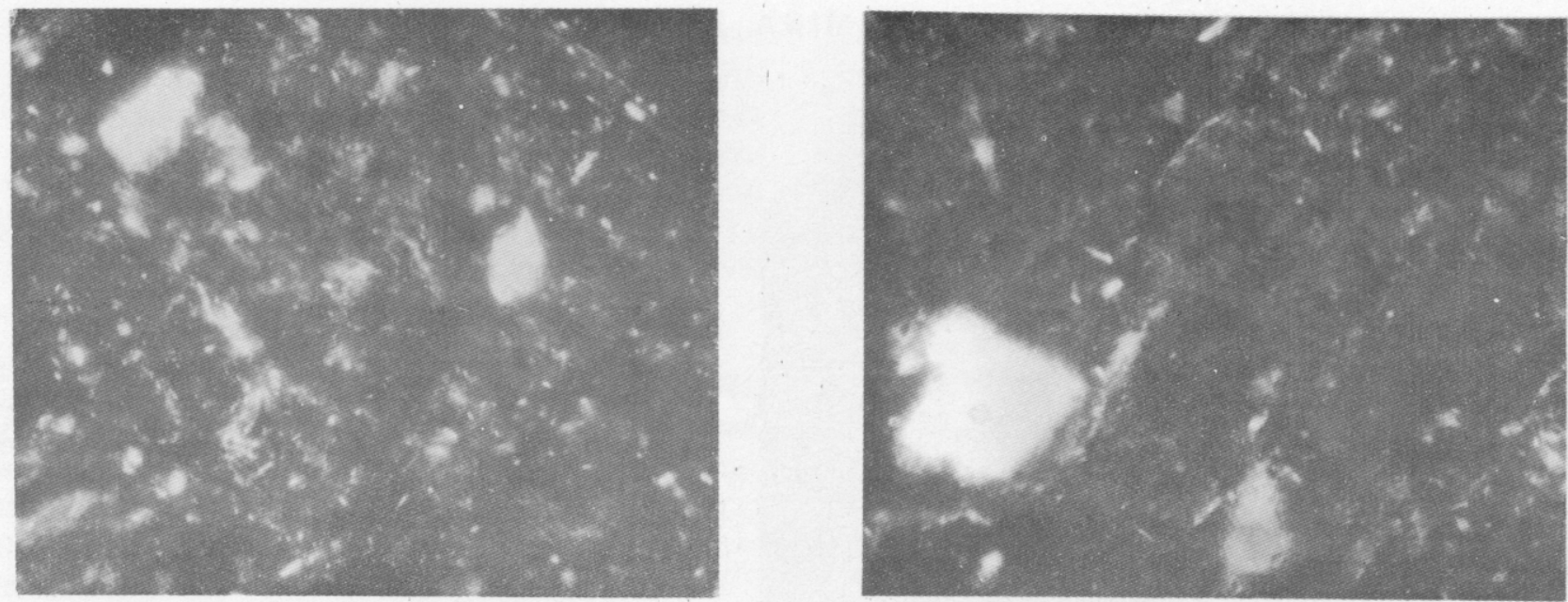

Figs.- 1 y 2.- Muestras los relictos de fragmentos de vidrio totalmente zeolitizados en la toba híbrida que forma el depósito.

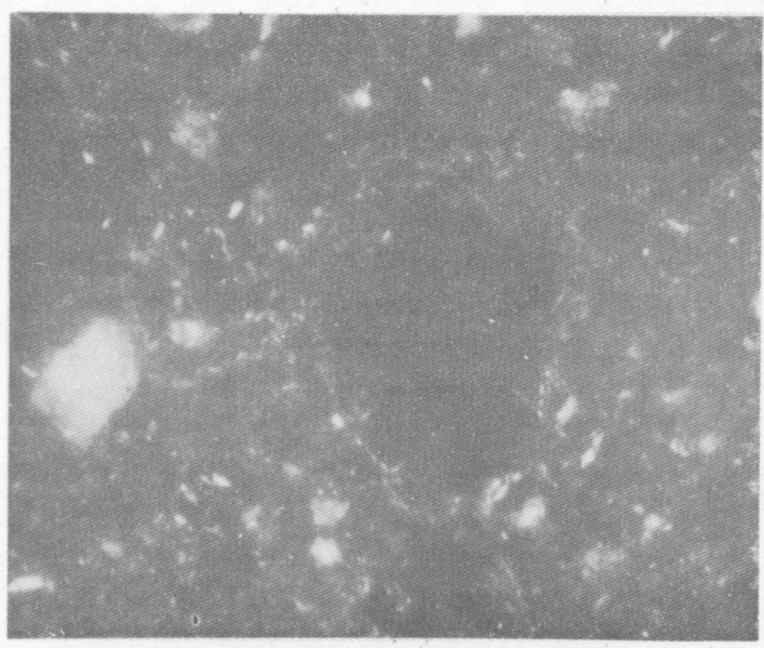

Fig. 3.- Fragmentos de vidrio zeolitizado a través de sus bordes.

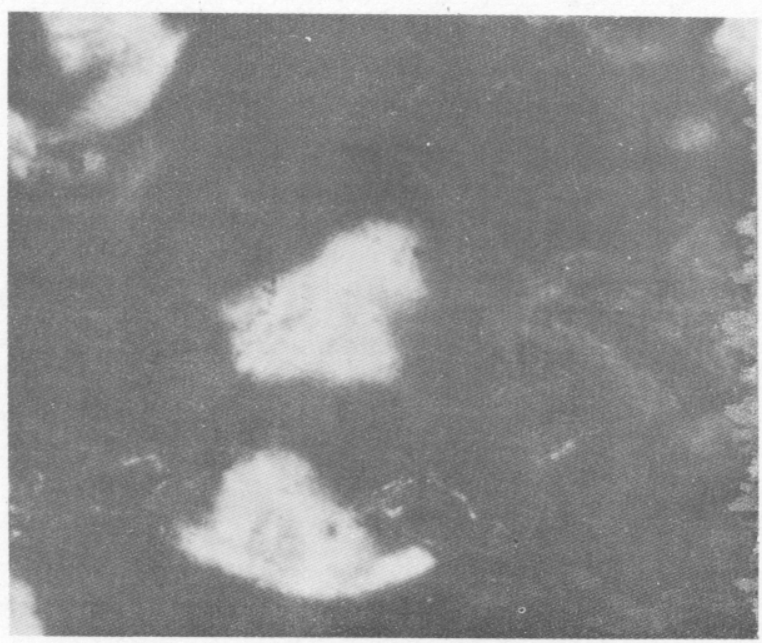

Fig. 5.- Fragmentos de feldespatos y vidrio parcialmente zeolitizados, los primeros a través de sus bordes y los segundos a través de sus bordes y fracturas.

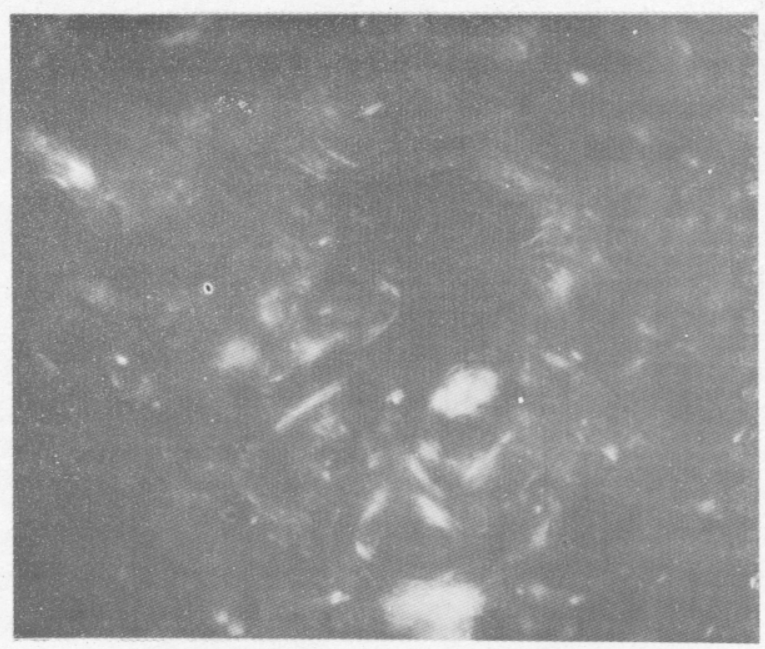

Fig. 4. - Fragmentos de vidrio zeolitizado a través de sus bordes $y$ fracturas.

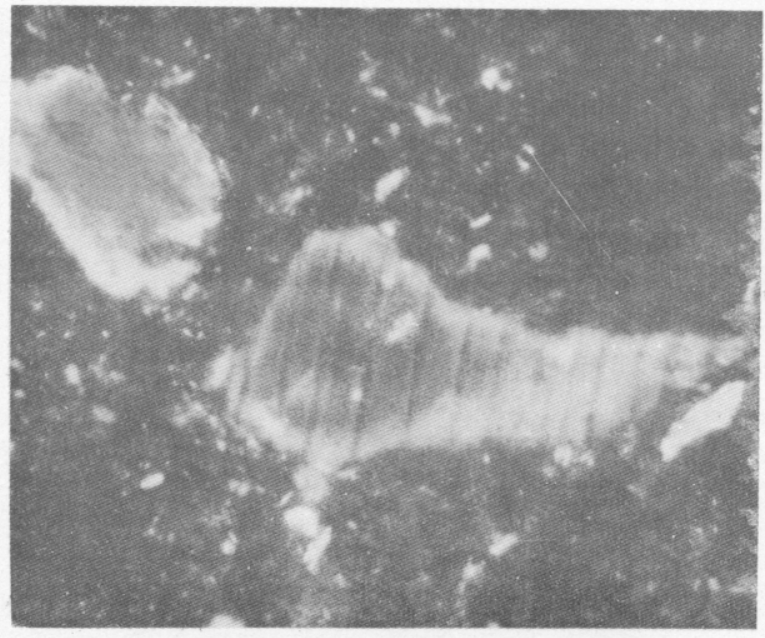

Fig. 6. - Fragmento de plagioclasa zeolitizada a través de sus bordes y ùe biotita cloritizada.

Nota: Tomadas en el microscopio petrográfico en lámina delgada, con nícoles cruzados. Amplificación $200 \mathrm{X}$. 


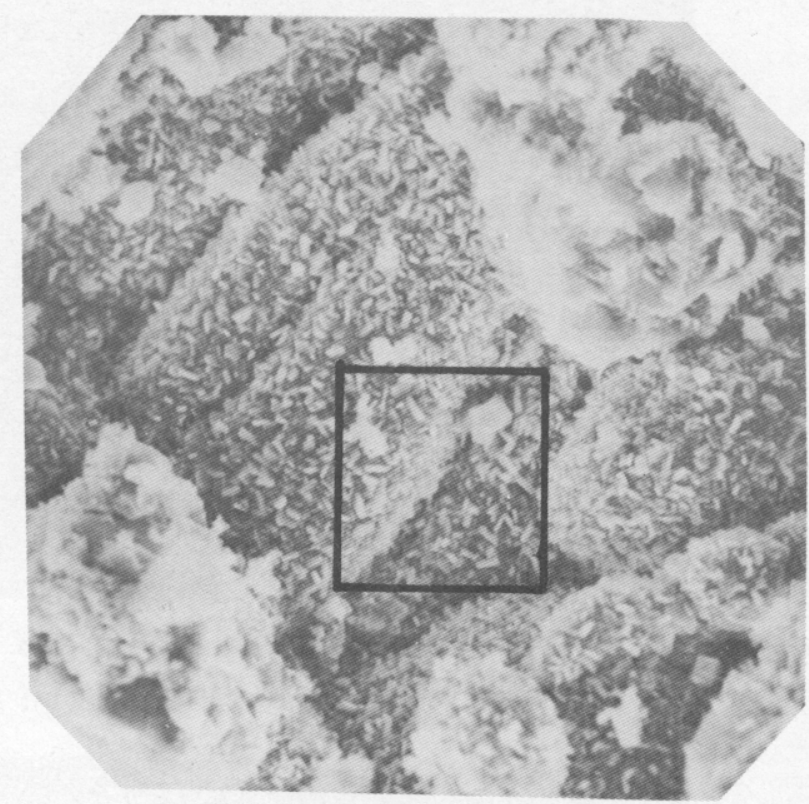

Fig. 1.- Muestra la zeolitización de los componentes de la toba híbrida. Tomada en el Microscopio Electrónico de Barrido con electrones secundarios en un fragmento recubierto con carbón, amplificación $285 X$.

Fig. 2.- Es un recuadro de la anterior donde se puede apreciar con mayor detalle la zeolitización entre dos granos contiguos Tomada en el Microscopio Electrónico de Barrido, amplificación 1019X.
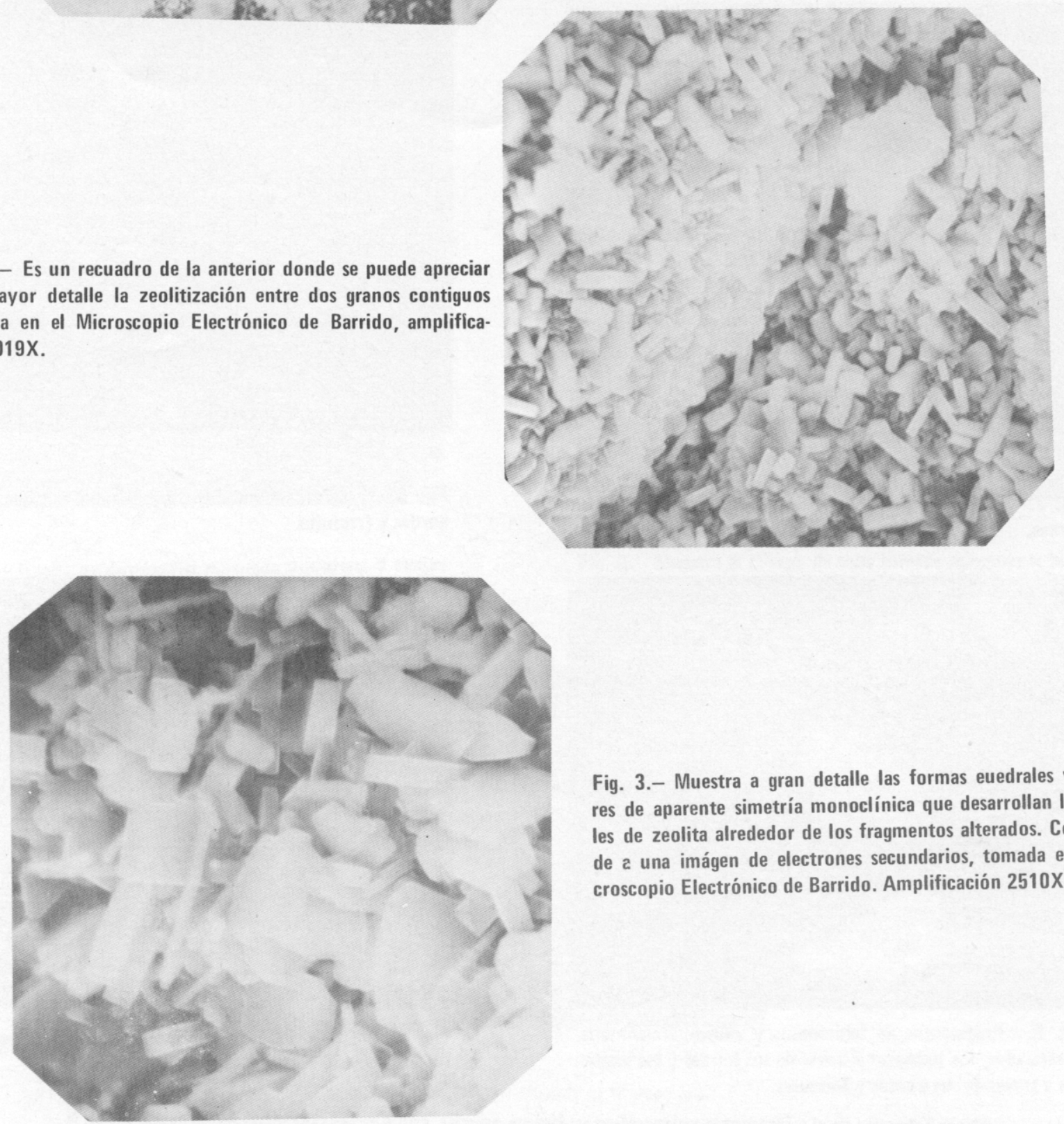

Fig. 3.- Muestra a gran detalle las formas euedrales y tabulares de aparente simetría monoclínica que desarrollan los cristales de zeolita alrededor de los fragmentos alterados. Corresponde a una imágen de electrones secundarios, tomada en un Microscopio Electrónico de Barrido. Amplificación 2510X. 
drio de la unidad de arenisca tobácea y no se hubiera efectuado con mayor energía en ciertos cuerpos estratiformes.

En vista de lo anterior, el yacimiento de zeolita de Ures, Sonora, corresponde a un depósito formado en un sistema "abierto" en un lago de agua dulce, de acuerdo a la clasificación propuesta por Mumpton (1976).

\section{CONCLUSIONES Y RECOMENDACIONES}

Los estudios anteriores permitieron llegar a las siguientes conclusiones y recomendaciones genéticas, mineralógicas y económicas del yacimiento:

1) El yacimiento corresponde a un cuerpo estratiforme de Toba Híbrida Zeolitizada, que se encuentra encajonado por una arenisca tobácea zeolitizada.

2) La zeolita que constituye el depósito fue caracterizada como clinoptilolita-heulandita, ya que en las pruebas recomendadas por diversos investigadores tendientes a discriminar una especie de otra, los resultados no fueron concluyentes para ninguna de las dos, por lo que los autores decidieron considerarla como un tipo intermedio.

3) En base a los estudios mineralógicos y texturales efectuados en los microscopios petrográfico $y$ electrónico de barrido y en difracción de rayos $\mathrm{X}$, se determinó que la zeolita se originó principalmente por reemplazamiento guiado de vidrio volcánico, desarrollado a través de bordes y fracturas de los fragmentos.

4) Los estudios texturales, estructurales y petrográficos efectuados a la unidad que encajona al yacimiento y a él mismo, nos permiten concluir que el material primario del que se originó el yacimiento fue depositado en un ambiente lacustre de agua dulce; otra evidencia más que refuerza lo anteriormente expresado es el tipo de zeolita que constituye al depósito y su zoneamiento mineralógico vertical.

5) Se recomienda hacer un estudio detallado del yacimiento tendiente a determinar sus reservas.

6) Hacerle un estudio de zoneamiento mineralógico lateral con el propósito de reconstruir los distintos ambientes paleogeográficos del lago.

7) Realizar una investigación metalúrgica exhaustiva del depósito, con objeto de efectuar la concentración de la zeolita.
8) Realizarle a los concentrados de zeolita obtenidos en el inciso anterior, pruebas físicas tales como capacidad de intercambio iónico, poder de absorción, tamaño de sus poros intermoleculares, etc., con objeto de determinarle sus principales usos.

9) Efectuar un estudio de viabilidad económica del depósito para conocer si es rentable su explotación.

\section{AGRADECIMIENTOS}

Los autores desean expresar su reconocimiento al Ing. Luis Espinosa de León, ex-director de la Unidad Tecamachalco de la Comisión de Fomento Minero, por el apoyo moral y material brindado para la realización del trabajo de campo; así como a los Ings. Adolfo Langenscheidt, Ramón Fernández y Víctor Manuel López, por las facilidades otorgadas en diferentes fases de la investigación. Igualmente agradecen su colaboración al $\mathrm{Sr}$. Leobardo Gamíz C. por la obtención de las imágenes en Microscopio Electrónico de Barrido y a todas las personas que directa o indirectamente ayudaron a la realización del presente estudio.

\section{REFERENCIAS BIBLIOGRAFICAS}

ALIETTI, A., 1972 Polymorphism and crystal-chemistry of heulendites and clinoptilolites, Amer, Mineral v. 57, pp. 1437-1461

BOLES, J.R., 1972, Composition, optical properties, cell dimensions and thermal stablitity of some houlendite group zeolites, Amer. Mineral., v. 57, pp. 1463-1493.

MUMPTON, F.A., 1960, Clinoptllolite redefined, Amer. Mineral., v. 45, pp. 351-369.

$-1973 s_{\text {, }}$ First reported occurrence of zeolites in sedimentary rocks of Mexico, Amer. Mineral., v. 58, pp. 287-290.

-1975, Zeolitle tuffs in the vicinity of Oaxees, M6xico, Libreto gu fa excursión "Tropical Soils", Intnal. Clays Conf., Clay Min. Soc., Inst. Geol. UNAM, pp. 45-51.

-1976. Morphology of zeolites in sedimentery rocks by scanning electron microscopy, Clays and Clay Min., v. 24, No. 1, pp. 1-52.

MUNSON, R.A., Sheppard, R.A., 1974, Natural Zeolites: Their properties, occurrences and uses, Min. Sci. Eng., v. 6, No. 1, pp. 19-34. 